\title{
The Slope of the Euro Area Phillips Curve: Always and Everywhere the
} Same?

\author{
Johanna Amberger ${ }^{1}$, Ralf Fendel ${ }^{1}$ \\ ${ }^{1}$ WHU-Otto Beisheim School of Management, Germany \\ Correspondence: Ralf Fendel, Department of Economics, WHU-Otto Beisheim School of Management, Burgplatz 2, \\ 56179 Vallendar, Germany.
}

Received: February 3, 2017

Accepted: March 16, $2017 \quad$ Available online: March 23, 2017

doi:10.11114/aef.v4i3.2296

URL: https://doi.org/10.11114/aef.v4i3.2296

\begin{abstract}
To determine whether the sensitivity of inflation to changes in the business cycle varies over time, hybrid new Keynesian Phillips curves are formulated in state space form and estimated via the Kalman filter. Analyses cover the Euro Area aggregate and eleven Euro Area countries. Results confirm the increasingly important role of inflation expectations. While the Phillips curve flattens until 2007, slope coefficients increase considerably with the financial crisis in 2007/08 on the basis of output gaps. Nonetheless, stable or decreasing slope coefficients are observed on the basis of unemployment gaps, indicating strong dependence on the driving variable used in estimations. Overall, differences in cross-country Phillips curve parameters are decreasing, indicating a convergence of Euro Area countries' inflation dynamics since 1990.
\end{abstract}

Keywords: time-varying Phillips curve, inflation dynamics, output gap, unemployment gap

\section{JEL Classification E31 E32}

\section{Introduction}

Recent inflation developments have led to two puzzling observations in the Euro Area (EA): During the sovereign debt crisis, inflation has remained fairly stable despite rising disinflationary cyclical pressure, but disinflation has been significant in periods thereafter. Both, the 'missing disinflation' between 2009 and 2011 and the 'excessive disinflation' after 2012 have not been foreseen by professional forecasters leading to a respective under- and overshooting of inflation expectations in recent years. Understanding current inflation dynamics on the basis of the Phillips curve is thus fundamental for the European Central Bank's (ECB's) primary goal of price stability as part of the two pillar strategy. Our analyses model inflation dynamics in 11 EA countries as well as the EA aggregate on the basis of time-varying hybrid New Keynesian Phillips curves (NKPCs) in order to identify possible changes in the transmission mechanism. At the same time, comparing inflation dynamics across EA member countries allows to determine converging effects in the degree of forward- and backward-looking price setting as well the slope of the Phillips curve over time. In the past 17 years of the EA, single monetary policy and increasing interdependencies are hypothesized to have a harmonizing effect on inflation dynamics in member states.

Three important findings emerge: First, inflation is increasingly driven by inflation expectations almost uniformly across all EA countries. Second, a flattening of the Phillips curve is observed only until 2007. Output gap coefficients have risen considerably in the course of the financial and sovereign debt crisis and have levelled off in 2012. In contrast, unemployment gaps indicate no uniform trend and remain largely stable. Third, EA countries' inflation dynamics are indeed assimilating as forward-looking price setting and output gap effects are converging since 1990.

Results of time-varying Phillips curves allow a better understanding of current inflation developments and confirm the effectiveness of monetary policy actions. The analyses contribute to current research by confirming rising slope coefficients based on output but not on unemployment gap specifications. This differentiation has not been emphasized before in comparative time-sensitive estimations and suggests a careful choice of real marginal cost measure used. Despite a common monetary policy, understanding inflation formation at the EA country level is necessary and beneficial for the control of EA aggregate inflation. Here, analyses across 11 EA countries indicate converging Phillips curve parameters. This novel finding validates research at the country level, but at the same time confirms and facilitates common monetary policy at the supranational level. 
The rest of the paper is structured as follows: Section 2 provides an overview on the related literature. Section 3 outlines relevant data, while Section 4 describes the estimation model and analyses' results. Section 5 presents alternative estimations and a discussion of results. Finally, Section 6 concludes.

\section{Literature Review}

The hybrid NKPC introduced by Galí and Gertler (1999) and extended by Galí et al. (2001) is explicitly based on microfoundations and models inflation dynamics as the result of both, back- and forward-looking price setting. While one share of economic agents sets prices according to future expected prices, the other share sets prices according to a backward-looking rule of thumb (Galí and Gertler, 1999) or indexation of lagged inflation (Christiano et al., 2005). As expected future prices in $t+1$ are not directly observable in period $t$, expected inflation is often replaced by ex post observed inflation in $t$, assuming rational expectation formation in the previous period $t-1$. With respect to limited model performance (compare Rudd and Whelan (2005)) and in order to circumvent the potentially weak assumption of rational expectation formation, survey measures of inflation expectations are increasingly included in hybrid NKPC estimations (e.g Paloviita (2008) and Montoya and Doehring (2011) include Consensus Economics survey measures and Koop and Onorante (2012) use results of the ECB's Survey of Professional Forecasters).

While estimating fixed-coefficient Phillips curves is important to generally map inflation formation, estimating time-varying coefficients is essential for the conduct of adequate and time-sensitive monetary policy. Inflation dynamics are not static, but vary according to underlying drivers such as nominal rigidities to the frequency of price adjustments (Riggi and Venditti, 2014), microeconomic volatility and resulting uncertainty (Vavra, 2014, Baley and Blanco, 2013), the level of inflation (Ball and Mazumder, 2011), temporary factors such as indirect taxes and commodity prices (European Commission, 2014), central bank credibility (IMF, 2013), and globalisation (Stevens, 2013).

In this context, a separate field of research on time-varying Phillips curves has emerged. Kichian (2001) is among the first to estimate the Phillips curve in state space form to assess the stability of Canadian inflation dynamics. A flattening of the Phillips curve is reported for countries of the EA (e.g. Oinonen et al. (2013), IMF (2013)) as well as the US (e.g. Ball and Mazumder (2011) and Matheson and Stavrev (2013)) for the time periods 1990s and early 2000s. Nonetheless, a reverse of this trend is found for the recent past. Based on EA aggregate data until Q2 2014, Oinonen and Paloviita (2014) find a sharp increase in the slope coefficient since 2012. Similarly, Álvarez and Urtasun (2013) report increased importance of the cyclical position in the recent past for Spain, which is confirmed by Riggi and Venditti (2014) for the EA, Italy, and France, but not for Germany. In line with these findings, the European Commission (2014) finds stronger output gap coefficients for the recent periods than before the crisis, especially in 'vulnerable' EA countries, i.e. Ireland, Greece, Spain, Cyprus, Portugal, and Slovenia. Further, Riggi and Venditti (2015) investigate the recent 2013/14 overshooting of Consensus Economics inflation forecasts and conclude either confirmed increases in slope coefficients in the respective period or imprecise measurement of current output gaps to be the reason.

Apart from changes in inflation's sensitivity to the business cycle, the degree of backward- and forward-looking price setting has shifted substantially. Forward-looking price setting has become increasingly important, as credible central bank policies result in better-anchored inflation expectations in the US (Stella and Stock, 2012) as well as the EA (Oinonen and Paloviita, 2014, European Commission, 2014, Stevens, 2013).

While increasing slope coefficients support Phillips curve models in targeting inflation and confirm the efficacy of the monetary transmission mechanism, their resurgence seems to partly depend on the measure of marginal cost used. In above discussed findings on increasing slope coefficients in the recent past, economic slack is largely represented by the output gap. In contrast, analyses including unemployment-related measures of real marginal cost confirm a flattening of the Phillips curve before and in the 1990s, but note remarkably stable slope coefficients thereafter (compare IMF (2013), Blanchard et al. (2015)). Nonetheless, Stella and Stock (2012) report a steeping of the Phillips curve in the US since 2008 based on multivariate unobserved component model. Possibly diverging slope coefficient evolution, depending on measures used, mark an important aspect in Phillips curve specification choice and are thus emphasized in our following analyses.

From a methodical point of view, different estimation methods have been suggested to estimate time-varying Phillips curves: Rolling regressions allow estimations on the basis of rolling time windows and are computationally simple. Even though the choice of window length corresponds to average business cycle length, it is chosen ad hoc and thus not necessarily ideal for all time series. While results are relatively independent of window length choices, e.g. 32 quarters (Oinonen et al., 2013), 30 quarters (Larkin, 2014), and 20 quarters (Álvarez and Urtasun, 2013), rolling regressions do not allow maximum coefficient flexibility. Further, extracting precise trends (of different driving variables) for EA countries (Amberger and Fendel, 2016) remains difficult. Estimating Phillips curves in state space form by means of the Kalman filter has emerged as a powerful alternative, allowing an optimal and flexible use of available data. Further, Riggi and Venditti (2014) include non-parametric estimators, Matheson and Stavrev (2013) base estimations on the non-linear Kalman filter, and Stella and Stock (2012) employ multivariate unobserved components stochastic volatility 
models estimated by Markov Chain Monte Carlo. Given the great flexibility of estimating Phillips curves in state space form, this method is also applied in the following analyses.

\section{Data}

Based on quarterly data from Q1 1990 to Q4 2015, hybrid NKPCs are estimated for eleven countries of the EA. The country set comprises the founding members, excluding Luxembourg and including Greece, which is not a founding member, but entered the EA slightly later in 2001. EA aggregate data corresponds to the weighted average of the eleven individual EA countries (EA11) (Note 1) in terms of quarterly changing Gross Domestic Product (GDP) weights. Only EA GDP is included as the sum of EA11 GDP.

Expected inflation is measured by private inflation forecasts from Consensus Economics (Note 2). Quarterly inflation expectations correspond to the weighted average of this and the coming year's inflation expectation in the first month of each quarter. The availability of Consensus forecasts limits the time series to the starting point in Q1 1990 and is the reason for excluding Luxembourg from analyses. Consensus Economics collects forecasts from a panel of different institutions in each country and publishes these under the name of the forecasting institution on a monthly basis. In order to account for changing panel size and composition, potential outliers as well as missing values, the mean of all forecasts for one country is included here. Despite the critique of formulating strategic forecasts, Consensus forecasts are generally reported to be unbiased and efficient forecasts (Dovern and Weisser, 2011) and widely used in related studies on inflation dynamics.

In line with the ECB's target of headline inflation and Consensus inflation forecasts, inflation is denoted as the annualized year-over-year change in the harmonized index of consumer prices (HICP). Figure 1 illustratively plots HICP inflation and survey measures of expected inflation from Consensus Economics for the EA. As reported by Constâncio (2015), inflation forecasts indeed underestimate inflation in 2010-12, but overestimate it since 2013 (also compare Riggi and Venditti (2015)) (Note 3).

With reference to potentially harmonizing effects of common monetary policy, Figure 1 also depicts the spread of minimum and maximum HICP inflation across EA11 over time. Indeed, inflation rate spreads decrease in anticipation of the Euro adoption. Despite a peak in the sovereign debt crisis in 2010, spreads remain relatively stable below 5\%.

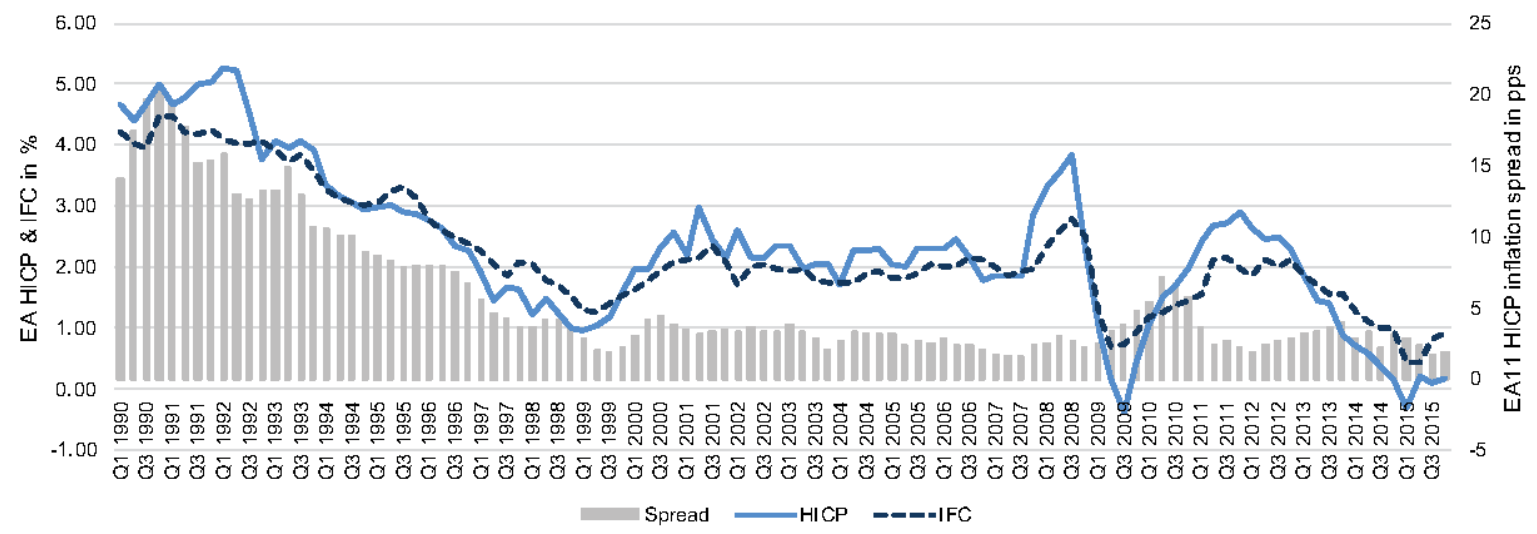

Figure 1. EA inflation, inflation expectations, and EA11 inflation spreads

Real marginal cost are represented by the output gap, derived as the percentage deviation of GDP from its potential. Potential GDP is determined on the basis of trend GDP as derived by the Hodrick-Prescott (HP) filter (Hodrick and Prescott, 1997) (Note 4). The unemployment gap, used as an alternative measure of real marginal cost in Section 5, is derived as the difference between countries' harmonized unemployment rates and respective non-accelerating inflation rates of unemployment (NAIRU) as estimated by the Organisation for Economic Co-operation and Development (OECD). The development of output and unemployment gaps is illustrated for the EA in Figure 2. 


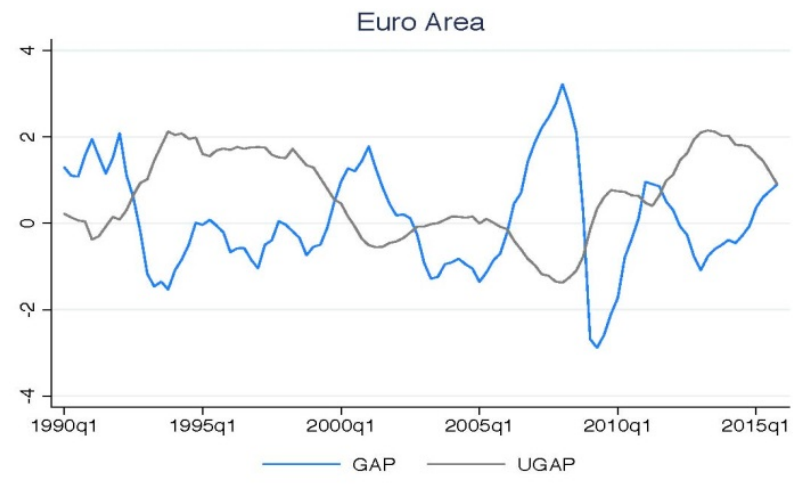

Figure 2. EA output and unemployment gap

Data is taken from Eurostat and complemented with information from the AMECO database and the European Commission where necessary (Note 5).

\section{Estimation Model and Results}

Analyses are based on the restricted hybrid NKPC denoted in equation (1). Restricting the coefficients of forward- and backward-looking price setting to one ensures a vertical Phillips curve in the long run and allows a direct comparison of price setting dynamics across EA countries. Further, it facilitates the evaluation of possibly converging price setting dynamics over time. In order to estimate time-invariant coefficients, (1) is estimated via General Method of Moments (GMM) to account for coefficient endogeneity. To allow for comparison with time-varying estimations, instrument sets are limited to lags of exogenous variables, i.e. inflation and the output gap. Newey-West (Newey and West, 1987) corrected standard errors with Bartlett (Newey-West) kernel of lag length four are reported to ensure robustness to heteroscedasticity and autocorrelation of unknown form.

$$
\pi_{t}=\gamma S_{t}\left(\pi_{t+1}\right)+(1-\gamma) \pi_{t-1}+\lambda g a p_{t}+\varepsilon_{t}
$$

Here, inflation $\pi_{t}$ is estimated to be the result of expected inflation $S_{t}\left(\pi_{t+1}\right)$ and past inflation $\pi_{t-1}$, a measure of the state of the business cycle, here the output gap gapt, as well as the error term $\varepsilon_{t}$. In order to estimate time-varying coefficients of Phillips curve parameters, (1) is written in state space form:

$$
\begin{gathered}
\pi_{t}=\gamma_{t} S_{t}\left(\pi_{t+1}\right)+\left(1-\gamma_{t}\right) \pi_{t-1}+\lambda_{t} g a p_{t}+\varepsilon_{t} \\
\gamma_{t}=\gamma_{t-1}+\eta_{1 t} \\
\lambda_{t}=\lambda_{t-1}+\eta_{2 t}
\end{gathered}
$$

Observation equation (2) models inflation on the basis of the restricted hybrid NKPC, while state equations (3) and (4) describe respective parameters $\gamma$ and $\lambda$ to follow a random walk. Error terms $\varepsilon_{t}$ and $\eta_{t t}$ for all $i=1,2$ are assumed to be uncorrelated at all lags and leads and normally distributed. Based on Kalman filtering techniques, time-varying parameters are estimated and updated each period (Note 6).

Estimation results of the hybrid NKPC with fixed coefficients serve as a benchmark for estimations of time-varying coefficient hybrid NKPCs. Table 1 summarizes results of estimating equation (1) via GMM. 
Table 1. Hybrid NKPC incl. output gap - GMM estimation

\begin{tabular}{|c|c|c|c|c|c|c|}
\hline \multicolumn{7}{|c|}{ HICP inflation } \\
\hline Country & $\mathbf{n}$ & $\gamma$ & $\lambda$ & J-statistic & F-Statistic & Instrument Set \\
\hline EA11 & 101 & $0.2477 * *,(0.0848)$ & $0.0940 * *,(0.0303)$ & $10.2013, \mathrm{p}=0.1164$ & 84.4700, Tau $<5 \%$ & L2-L4.HICP,L1-L4.GAP \\
\hline Austria & 101 & $0.4418 * * *,(0.1199)$ & $0.1435^{* * * *},(0.0382)$ & $6.4651, p=0.3732$ & $30.5560, \mathrm{Tau}<10 \%$ & L2-L4.HICP, L1-L4.GAP \\
\hline Belgium & 101 & $0.2773^{* *},(0.1062)$ & $0.1725^{*},(0.0881)$ & $9.2956, p=0.1576$ & $10.4700, \mathrm{Tau}<30 \%$ & L2-L4.HICP, L1-L4.GAP \\
\hline Finland & 101 & $0.2497 * *,(0.0835)$ & $0.0985^{* * *},(0.0214)$ & $4.0602, p=0.6685$ & $12.6840, \mathrm{Tau}<20 \%$ & L2-L4.HICP, L1-L4.GAP \\
\hline France & 101 & $0.2310,(0.1195)$ & $0.1377^{*},(0.0556)$ & $6.8276, p=0.3371$ & $11.1810, \mathrm{Tau}<30 \%$ & L2-L4.HICP, L1-L4.GAP \\
\hline Germany & 101 & $0.1843^{*},(0.0824)$ & $0.0658^{* *},(0.0230)$ & $8.4517, p=0.2068$ & $39.3400, \mathrm{Tau}<5 \%$ & L2-L4.HICP, L1-L4.GAP \\
\hline Greece & 90 & $0.2454,(0.2110)$ & $0.4821,(0.2867)$ & $0.0011, p=0.9994$ & $146.8890, \mathrm{Tau}<5 \%$ & L2-L4.HICP \\
\hline Ireland & 101 & $0.1363^{*},(0.0641)$ & $0.0346,(0.0249)$ & $5.2617, p=0.5107$ & $18.7030, \mathrm{Tau}<10 \%$ & L2-L4.HICP, L1-L4.GAP \\
\hline Italy & 101 & $0.1418,(0.1021)$ & $0.1400 * * *,(0.0337)$ & $11.4185, p=0.0763$ & $77.4030, \mathrm{Tau}<5 \%$ & L2-L4.HICP, L1-L4.GAP \\
\hline The Netherlands & 101 & $0.1483^{*},(0.0657)$ & $0.0996^{* *},(0.0387)$ & $9.5963, p=0.1427$ & 15.7070, $\mathrm{Tau}<20 \%$ & L2-L4.HICP, L1-L4.GAP \\
\hline Portugal & 101 & $0.3619 * * *,(0.0748)$ & $0.1690^{* * *},(0.0412)$ & $5.6785, \mathrm{p}=0.4602$ & $299.2160, \mathrm{Tau}<5 \%$ & L2-L4.HICP, L1-L4.GAP \\
\hline Spain & 101 & $0.2517 * *,(0.0864)$ & $0.0568,(0.0390)$ & $3.9014, p=0.6900$ & $37.4170, \mathrm{Tau}<5 \%$ & L2-L4.HICP, L1-L4.GAP \\
\hline
\end{tabular}

GMM coefficient estimates with Newey-West HAC corrected standard errors in italic. Stars indicate significance at the $* \mathrm{p} \leq 0.05, * * \mathrm{p} \leq 0.01$, and $* * * \mathrm{p} \leq 0.001$ level. J-statistic corresponds to Hansen J-test of overidentifying restrictions. Results of the Montiel-Pflueger weak instrument test are reported as F-statistic. Tau represents the \% of worst case bias.

Instrument sets based on individual countries' correlation statistics with the endogenous variable. L1 - L4 indicate first to fourth lag of respective variables. Sample sizes vary slightly due to data availability.

Forward-looking price setting is still weak in the EA with $\gamma=0.25$ as well as the 11 EA countries with $\gamma$ ranging from 0.14 to 0.44 . While Austria and Portugal are characterized by comparably strong forward-looking coefficients, Ireland, Italy, and the Netherlands are among the most backward-looking countries. Output gap coefficients are positive and significant in nine out of twelve cases, ranging from 0.07 to 0.17 . Largely backward-looking price setting and positive gap coefficients are in line with results reported in similar studies on EA inflation dynamics (e.g. Henzel and Wollmershaeuser (2008), Montoya and Doehring (2011)). Testing for overidentifying restrictions on the basis of the Hansen J-test (Hansen, 1982) indicates them to be valid. Similarly, instrument sets can by and large be considered strong on the basis of Montiel \& Pflueger weak instrument tests (Montiel Olea and Pflueger, 2013). Here, the hypothesis of weak instruments cannot be rejected at the $10 \%$ confidence level only in Belgium, Finland, France, and the Netherlands.

Estimating the hybrid NKPC in state space form by means of the Kalman filter exhibits parameters $\gamma$ and $\lambda$ to vary considerably over time. Figure 3 displays their variation over time. Coefficient $\gamma$ has increased during the crisis especially between 2008 and 2010 from relatively stable levels in the early 2000s. While forward-looking price setting increases in the majority of EA countries during the crisis, it remains stable in the Netherlands and, surprisingly, decreases in Greece and Portugal. In comparison to fixed-coefficient results, Ireland, Italy, and Spain are among the countries with highest shares of forward-looking prices setters and Finland the one with predominantly backward-looking price setting. In the recent past, coefficients $\gamma$ have increased by $+5 \%$ (the Netherlands) to $+189 \%$ (Ireland) from Q1 2007 to Q4 2015. Here, Austria, Finland, and Ireland all indicate coefficient increases by more than $100 \%$.

Central to this paper is the development of the slope coefficient over time. While the gap coefficient $\lambda$ decreases uniformly in all EA countries in the early 2000s, sometimes starting even earlier, it experiences a sharp increase with the onset of the financial crisis in 2007/08. Starting in 2009/10, this increase fades out and $\lambda$ stays at a new and higher level. Rising slope coefficients are observed for the EA area as a whole and for all EA11 countries individually except the Netherlands. Here, the flattening of Phillips curve during the 2000s fades out in 2007/08 and $\lambda$ remains stable at this level. Spain's gap coefficient, in contrast, indicates a reverse trend thereafter and decreases again slightly since 2012. 

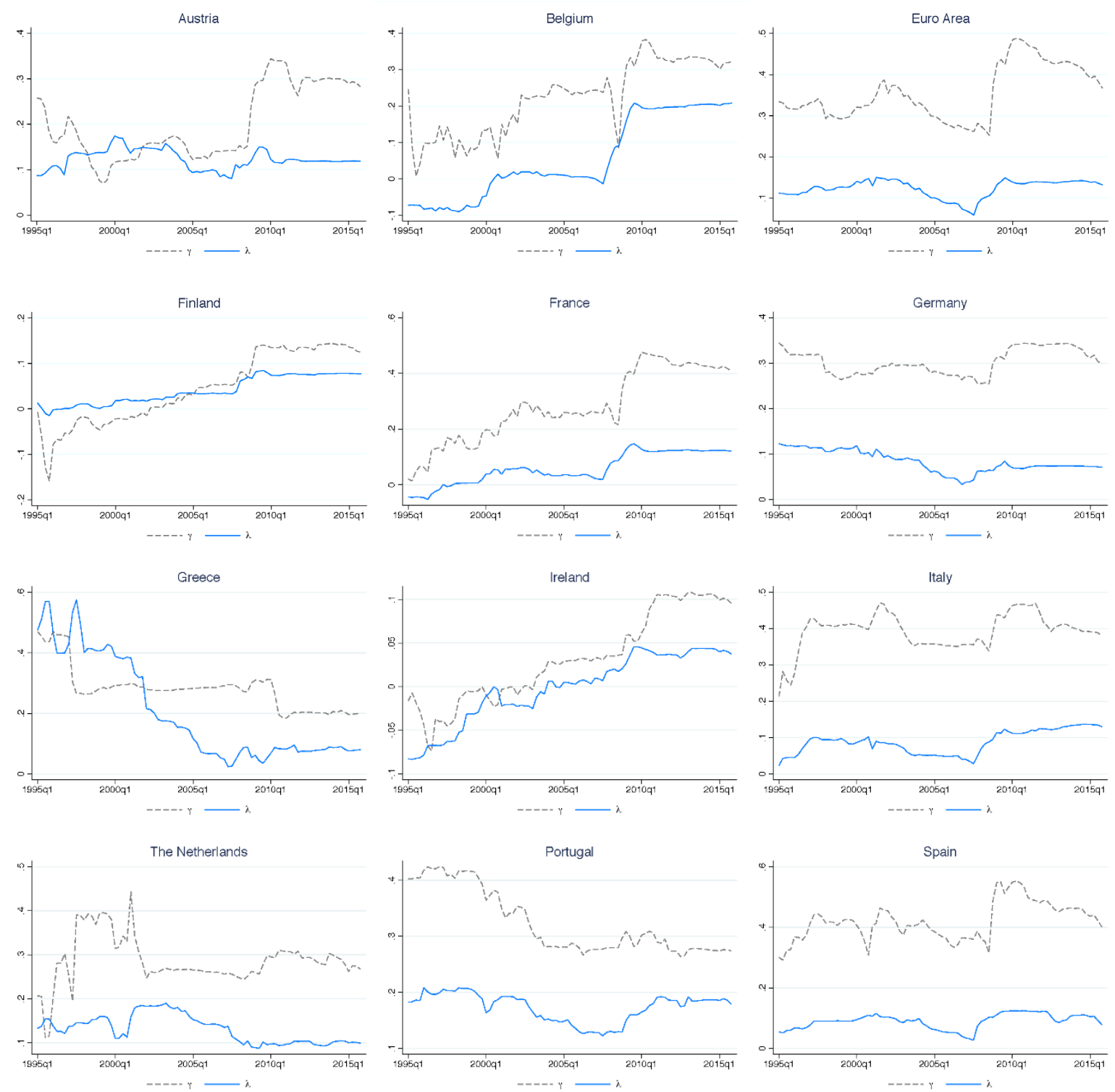

Figure 3. Hybrid NKPC including output gap - Kalman filter estimates

Compared to Q1 2007, gap coefficients $\lambda$ have increased in all countries except the Netherlands by $+33 \%$ (Austria) to $+432 \%$ (France) until Q4 2015. Slope coefficients of Finland, France, Ireland, Italy, and Spain more than doubled during this period, indicating considerable increases in the inflation-output tradeoff. Results thus partly confirm findings of the European Commission (2014) of strongest gap coefficient increases in 'vulnerable' countries of the EA. Fixedand time-varying coefficient estimates of $\gamma$ and $\lambda$ are generally of similar size. Nonetheless, fixed-coefficient estimates do not fully reflect recent increases in the role of inflation expectations and output gaps and thus remain slightly lower in the majority of EA countries for 2015.

As a result of a shared monetary policy since 1999 as well as increasing interdependencies across the EA, inflation dynamics are hypothesized to assimilate over time. While Figure 1 indicates decreasing spreads in inflation rates across the EA, Figure 4 plots the spread between minimum and maximum Phillips curve coefficients of EA and EA11 estimations over time. 


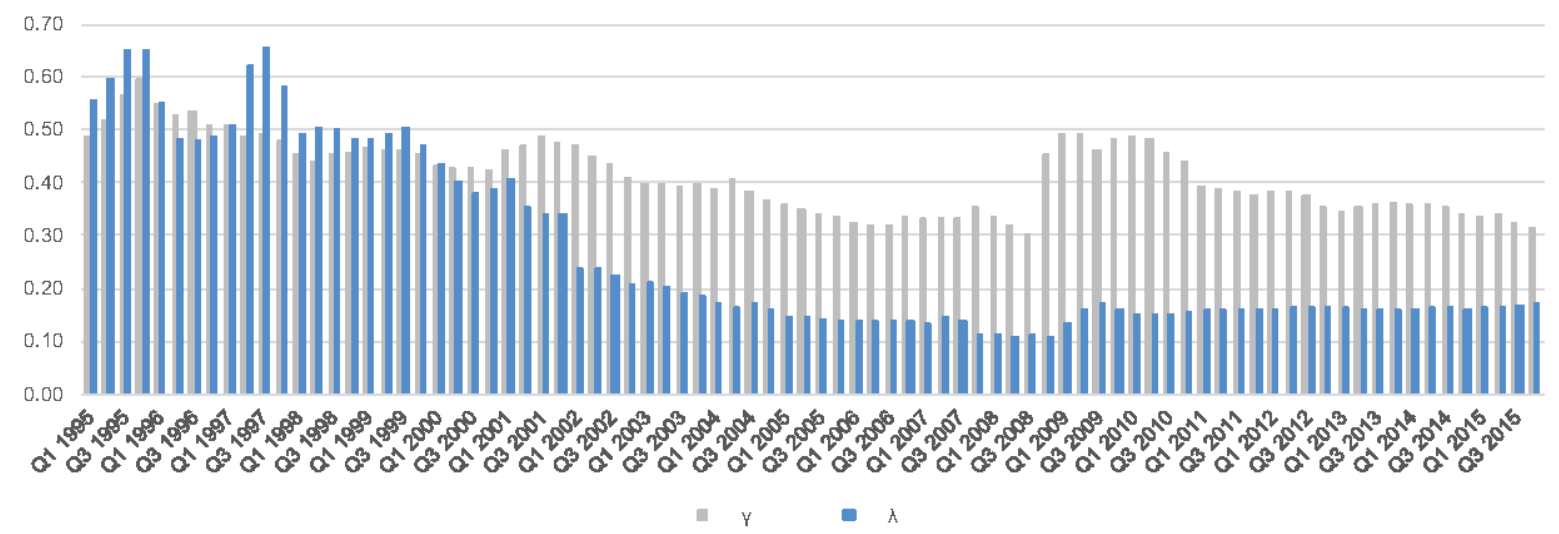

Figure 4. Hybrid NKPC incl. output gap - EA11 spreads (difference between min and max) of time-varying coefficients Taking the spread of Phillips curve coefficients as an indicator for heterogeneity indeed proves inflation dynamics to be converging over time. While the spread of the forward-looking term coefficient decreases $\gamma$ from around 0.60 in the early 1990s to 0.34 in 2014/15, the difference between maximum and minimum output gap coefficients $\lambda$ decreases from 0.50 to 0.17 . Despite small increases in both spreads in the course of 2008/09, Phillips curve coefficients point at harmonized developments across EA countries since the 1990s.

\section{Alternative Tests and Discussion}

Several alternative specifications of the hybrid NKPC are estimated to test the robustness of results. These include tests on both, fixed- as well as time-varying coefficient analyses.

First, Ordinary Least Square (OLS) and unrestricted estimations represent viable benchmarks to GMM results. Results of alternative estimations are summarized, but not illustrated in detail given broad conformance with findings reported in Section 4. Due to assumed coefficient endogeneity, estimations are based on GMM estimators, which in turn correspond to OLS estimators in the absence thereof. OLS estimation results are indeed similar, albeit slightly larger and more significant coefficients. To test the viability of results in the absence of coefficient sum constraints, unrestricted hybrid NKPCs are estimated via GMM and in state space form as well. Unrestricted coefficients are generally in line with fixed- and time-varying coefficient results reported above. In time-varying estimations, smaller discrepancies only change the level of coefficients slightly. Most importantly, the increasing role of forward-looking price setting is confirmed by a simultaneously decreasing unrestricted coefficient of the backward-looking term in the vast majority of countries (Note 7).

Second, unemployment gaps are included as an alternative measure of real marginal cost. With respect to above described differences in the literature concerning the development of the slope coefficient, the unemployment gap specification, denoted in equation (5) serves as a direct comparison to the output gap specification.

$$
\pi_{t}=\gamma_{t} S_{t}\left(\pi_{t+1}\right)+\left(1-\gamma_{t}\right) \pi_{t-1}+\lambda_{t} u g a p_{t}+\varepsilon_{t}
$$

Estimating (5) via GMM yields fixed-coefficient estimates summarized in Table 2. Results confirm EA countries to be primarily backward-looking with the majority of $\gamma$ coefficients close to the above-described gap estimation results.

Coefficients of the unemployment gap are generally negative as expected and significant in only five out of twelve cases ranging from -0.03 (Greece) to -0.13 (Finland). In comparison to gap estimations, unemployment gaps are concluded to be slightly less informative for EA countries inflation dynamics, both in terms of magnitude and significance. 
Table 2. Hybrid NKPC incl. unemployment gap-GMM estimation

\begin{tabular}{|c|c|c|c|c|c|c|}
\hline \multicolumn{7}{|c|}{ HICP inflation } \\
\hline Country & $\mathbf{n}$ & $\gamma$ & $\lambda_{\text {ugap }}$ & J-statistic & F-Statistic & Instrument Set \\
\hline EA11 & 101 & $0.1973^{*},(0.0864)$ & $-0.1010 *,(0.0445)$ & $4.0797, p=0.1300$ & $91.6870, \mathrm{Tau}<5 \%$ & L2-L4.HICP \\
\hline Austria & 100 & $0.3347 * * *,(0.0998)$ & $-0.1243,(0.0645)$ & $5.6813, p=0.4598$ & $23.9650, \mathrm{Tau}<10 \%$ & L2-L4.HICP, L1-L4.UGAP \\
\hline Belgium & 100 & $0.3053 * *,(0.1122)$ & $-0.1333,(0.0796)$ & $8.7185, p=0.1900$ & $7.7890, \mathrm{Tau}>30 \%$ & L2-L4.HICP, L1-L4.UGAP \\
\hline Finland & 100 & $0.2440 *,(0.1032)$ & $-0.1342 * * *,(0.0332)$ & $3.4225, p=0.7543$ & $10.2980, \mathrm{Tau}<30 \%$ & L2-L4.HICP, L1-L4.UGAP \\
\hline France & 101 & $0.1856,(0.1033)$ & $-0.0236,(0.0368)$ & $6.1161, p=0.0470$ & $15.0670, \mathrm{Tau}<20 \%$ & L2-L4.HICP \\
\hline Germany & 96 & $0.2272 * *,(0.0827)$ & $-0.0408,(0.0518)$ & $9.0340, p=0.1717$ & $30.6210, \mathrm{Tau}<10 \%$ & L2-L4.HICP, L1-L4.UGAP \\
\hline Greece & 80 & $0.4741^{* * *},(0.1098)$ & $-0.0331 * *,(0.0125)$ & $4.1999, p=0.6497$ & 20.1080 , Tau $<10 \%$ & L2-L4.HICP, L1-L4.UGAP \\
\hline Ireland & 100 & $0.1517^{*},(0.0599)$ & $-0.0261,(0.0224)$ & $7.2910, p=0.2948$ & 16.4240, $\mathrm{Tau}<20 \%$ & L2-L4.HICP, L1-L4.UGAP \\
\hline Italy & 100 & $0.1748,(0.0962)$ & $-0.0283,(0.0307)$ & $10.8806, p=0.0921$ & 55.7570, Tau $<5 \%$ & L2-L4.HICP, L1-L4.UGAP \\
\hline The Netherlands & 100 & $0.2964 * * *,(0.0764)$ & $-0.1052^{*},(0.0530)$ & $10.2541, \mathrm{p}=0.1144$ & $11.9580, \mathrm{Tau}<20 \%$ & L2-L4.HICP, L1-L4.UGAP \\
\hline Portugal & 100 & $0.4251^{* * *},(0.0905)$ & $-0.0925 * *,(0.0301)$ & $5.6803, \mathrm{p}=0.4599$ & $171.6260, \mathrm{Tau}<5 \%$ & L2-L4.HICP, L1-L4.UGAP \\
\hline Spain & 101 & $0.2544 * *,(0.0976)$ & $-0.0274,(0.0399)$ & $3.2380, p=0.1981$ & $84.0590, \mathrm{Tau}<5 \%$ & L2-L4.HICP \\
\hline
\end{tabular}

GMM coefficient estimates with Newey-West HAC corrected standard errors in italic. Stars indicate significance at the $* \mathrm{p} \leq 0.05, * * \mathrm{p} \leq 0.01$, and $* * * \mathrm{p} \leq 0.001$ level. J-statistic corresponds to Hansen J-test of overidentifying restrictions. Results of the Montiel-Pflueger weak instrument test are reported as F-statistic. Tau represents the \% of worst case bias.

Instrument sets based on individual countries' correlation statistics with the endogenous variable. L1-L4 indicate first to fourth lag of respective variables. Sample sizes vary slightly due to data availability.

To estimate (5) in state space form, (2) and (3) in Section 4 are modified to include $\lambda_{t} u g a p_{t}$ instead of $\lambda_{t} g a p_{t}$ (Note 8). Time-varying estimations including unemployment gaps provide partly differing results as depicted in Figure 5. Increasingly forward-looking price setting is roughly confirmed in seven out of twelve countries. Coefficients $\gamma$ often exhibit a dip during the financial crisis in 2007/08 and post-2010 levels are very similar to levels in the 2000s. Further, no uniform trend can be observed for $\lambda_{\text {ugap }}$ across EA countries. While coefficients remain surprisingly stable in the EA, France, Italy, the Netherlands, and Spain, a flattening of the unemployment gap coefficient is observed Austria, Germany, Ireland, and Portugal. Slope coefficients have increased only in Belgium, Finland, and Greece. In contrast to increases of gap coefficients, increases in the slope coefficient take place gradually over time and do not seem to be directly related to periods of the crisis.

Overall, alternative estimations confirm the robustness of results, but also present interesting deviations. Analyses suggest the role of inflation expectations to have strengthened significantly over the past $\sim 20$ years to $\gamma$ roughly between 0.20 and 0.40 , nearly independent of the real marginal cost measure used. This finding is in line with the wide consensus of well-anchored inflation expectations. Interestingly, results support the hypothesis of differing slope coefficient developments depending on the measure of real marginal cost used. This hypothesis stems from directly contrasting different findings in the literature. While output gap coefficients increase considerably since 2007/08, unemployment gap coefficients remain stable or decrease in the majority of EA countries. This differentiation corresponds to various findings in the literature that report increasing inflation-output gap trade-offs in the recent past (among them Riggi and Venditti (2014), European Commission (2014), Constâncio (2015), Stevens (2015)), but rather stable inflation-unemployment trade-offs during the same periods (e.g. IMF (2013), Blanchard et al. (2015)) (Note 9). Consequently, the dependence of slope coefficients' evolution on the measure of real marginal cost used suggests caution in the Phillips curve specification choice. With reference to output gaps indicating broader significance, stronger inflation expectation terms, and greater consent with related studies, it may currently reflect the state of the business cycle in the EA more comprehensively than its unemployment gap counterpart. 

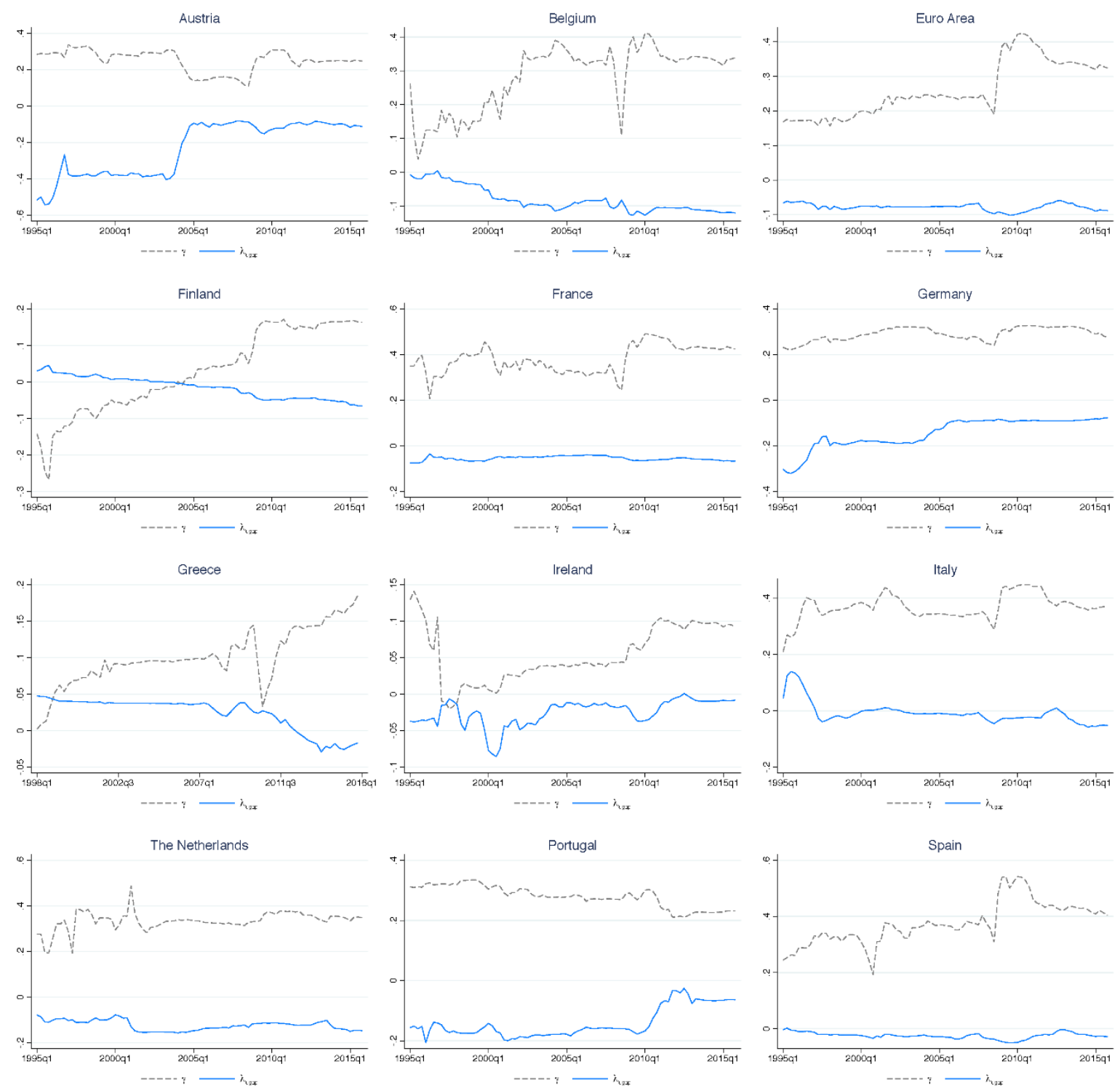

Figure 5. Hybrid NKPC including unemployment gap-Kalman filter estimates

\section{Conclusion}

Estimations indicate the Phillips curve relation to change considerably over time, which requires a continuous modification of the inflation expectation formation process as well as the conduct of monetary policy. To conclude, three important results are highlighted. First, inflation expectations play an increasingly important role in EA inflation dynamics, thereby proving them to be well-anchored. Second, while the relation between inflation and the output gap has strengthened during the recent financial crisis, the relation between inflation and the unemployment gap remains ambiguous across EA countries. With respect to the quality of estimations, output gaps are considered to be a valid choice of current business cycle state measure. Third, comparing the evolution of Phillips curve across EA countries indicates converging inflation dynamics since the 1990s.

Several factors may account for increased Phillips curve slope coefficients in the recent past. Apart from difficulties related to the precise measurement of potential output and consequently current output gaps potentially underestimating 'true' output gaps, fundamental changes are likely to play an important role. As the slope coefficient is a function of the frequency of price adjustments, enhanced wage flexibility and higher aggregate price flexibility due to higher uncertainty or microeconomic volatility potentially result in higher slope coefficients. Further, non-linearities in the inflation-output gap relation lead to increased sensitivities only in the case of persistently large output gaps.

The strengthened link between inflation and real activity reaffirms the Phillips curve and thus the effectiveness of monetary policy actions. Given the strong role of inflation expectations, particular emphasis is on the containment of stable inflation expectations to complement the traditional transmission mechanism. On a more general note, 
synchronizing inflation dynamics suggest favorable effects of a uniform monetary policy, which counters 'one size fits all' critiques and facilitates common monetary policy in the future. While results indicate converging trends, precise measurement of convergence and its determinants present an interesting field for further research.

\section{References}

Álvarez, L. J., \& Urtasun, A. (2013). Variation in the cyclical sensitivity of Spanish inflation: An initial approximation. Banco de Espana Economic Bulletin, July-August:11-17.

Amberger, J., \& Fendel, R. (2016). Understanding inflation dynamics in the Euro Area: Deviants and commonalities across member countries. Empirica Journal of European Economics, forthcoming. https://doi.org/10.1007/s10663-016-9322-x

Baley, I., \& Blanco, J. A. (2013). Learning to price. Contribution to 4th Ifo Conference on Macroeconomics and Survey Data, December 2013.

Ball, L. M., \& Mazumder, S. (2011). Inflation dynamics and the great recession. National Bureau of Economic Research Working Paper, 17044. https://doi.org/10.3386/w17044

Blanchard, O., Cerutti, E., \& Summers, L. (2015). Inflation and activity-two explorations and their monetary policy implications. IMF Working Paper, 15/230. https://doi.org/10.5089/9781513536613.001

Christiano, L. J., Eichenbaum, M., \& Evans, C. L. (2005). Nominal rigidities and the dynamic effects of a shock to monetary policy. Journal of Political Economy, 113(1), 1-45. https://doi.org/10.1086/426038

Coibion, O., \& Gorodnichenko, Y. (2015). Is the Phillips curve alive and well after all? Inflation expectations and the missing disinflation. American Economic Journal: Macroeconomics, 7(1), 197-232. https://doi.org/10.1257/mac.20130306

Constâncio, V. (2015). Understanding inflation dynamics and monetary policy. https://www.ecb.europa.eu/ press/key/date/2015/html/sp150829.en.html. Panel remarks Jackson Hole Economic Policy Symposium.

Dovern, J., \& Weisser, J. (2011). Accuracy, unbiasedness and efficiency of professional macroeconomic forecasts: An empirical comparison for the G7. International Journal of Forecasting, 27(2), 452-465. https://doi.org/10.1016/j.ijforecast.2010.05.016

European Commission (2014). Analysing current disinflationary trends in the Euro Area. European Economy: European Economic Forecast, 2/2014.

Galí, J., \& Gertler, M. L. (1999). Inflation dynamics: A structural econometric analysis. Journal of Monetary Economics, 44(2), 195-222. https://doi.org/10.1016/S0304-3932(99)00023-9

Galí, J., Gertler, M., \& Lopez-Salido, J. D. (2001). European inflation dynamics. European Economic Review, 45(7), 1237-1270. https://doi.org/10.1016/S0014-2921(00)00105-7

Hansen, L. P. (1982). Large sample properties of generalized method of moments estimators. Econometrica, 50(4), 1029-1054. https://doi.org/10.2307/1912775

Henzel, S., \& Wollmershaeuser, T. (2008). The new Keynesian Phillips curve and the role of expectations: Evidence from the Ifo World Economic Survey. Economic Modelling, 25(5), 811-832. https://doi.org/10.1016/j.econmod.2007.11.010

Hodrick, R. J., \& Prescott, E. C. (1997). Postwar US business cycles: An empirical investigation. Journal of Money, Credit and Banking, 29(1), 1-16. https://doi.org/10.2307/2953682

IMF (2013). The dog that didn't bark: Has inflation been muzzled or was it just sleeping. IMF World Economic Outlook, April (Chapter 3), 1-17.

Kichian, M. (2001). On the nature and the stability of the Canadian Phillips curve. Bank of Canada Working Paper, 4.

Koop, G. ,\& Onorante, L. (2012). Estimating Phillips curves in turbulent times using the ECB's Survey of Professional Forecasters. ECB Working Paper Series, 1422, 1-37.

Larkin, J. (2014). Examining the sensitivity of inflation to the output gap across Euro Area member states. Central Bank of Ireland Quarterly Bulletin, Q2(April), 50-51.

Matheson, T., \& Stavrev, E. (2013). The great recession and the inflation puzzle. Economic Letters, 120, 468-472. https://doi.org/10.1016/j.econlet.2013.06.001

Montiel Olea, J. L., \& Pflueger, C. (2013). A robust test for weak instruments. Journal of Business and Economic Statistics, 31(3), 358-369. https://doi.org/10.1080/00401706.2013.806694 
Montoya, L. A., \& Doehring, B. (2011). The improbable renaissance of the Phillips curve: The crisis and Euro Area inflation dynamics. European Commission Economic Papers, 446, 1-34.

Newey, W. K., \& West, K. D. (1987). A simple, positive semi-definite, heteroskedasticity and autocorrelation consistent covariance matrix. Econometrica, 55(3), 703-708. https://doi.org/10.2307/1913610

Oinonen, S., \& Paloviita, M. (2014). Updating the Euro Area Phillips curve: The slope has increased. Bank of Finland Research Discussion Paper, 31. https://doi.org/10.2139/ssrn.2545356

Oinonen, S., Paloviita, M., \& Vilmi, L. (2013). How have inflation dynamics changed over time? Evidence from the Euro Area and USA. Bank of Finland Research Discussion Paper, 6. https://doi.org/10.2139/ssrn.2268417

Paloviita, M. (2008). Estimating open economy Phillips curves for the Euro Area with directly measured expectations. Bank of Finland Research Discussion Papers, 16/2008, 1-35. https://doi.org/10.2139/ssrn.1153332

Riggi, M., \& Venditti, F. (2014). Surprise! Euro Area inflation has fallen. Bank of Italy Occasional Paper, 237. https://doi.org/10.2139/ssrn.2575673

Riggi, M., \& Venditti, F. (2015). Failing to forecast low inflation and Phillips curve instability: A Euro-Area perspective. International Finance, 18(1), 47-67. https://doi.org/10.1111/1468-2362.12062

Rudd, J., \& Whelan, K. (2005). New tests of the new-Keynesian Phillips curve. Journal of Monetary Economics, 52(6), 1167-1181. https://doi.org/10.1016/j.jmoneco.2005.08.006

Stella, A., \& Stock, J. H. (2012). A state-dependent model for inflation forecasting. Board of Governors of the Federal Reserve System International Finance Discussion Papers, 1062. https://doi.org/10.2139/ssrn.2184946

Stevens, A. (2013). What inflation developments reveal about the Phillips curve: Implications for monetary policy. National Bank of Belgium Economic Review, December 2013, 67-76.

Vavra, J. S. (2014). Time-varying Phillips curves. National Bureau of Economic Research Working Paper, 19790. https://doi.org/10.3386/w19790 


\section{Notes}

Note 1: EA11 thus comprises Austria, Belgium, Finland, France, Germany, Greece, Ireland, Italy, the Netherlands, Portugal, and Spain.

Note 2: Instead of relying on inflation expectations of professional forecasters, Coibion and Gorodnichenko (2015) suggest household inflation expectations to better approximate firms' inflation expectations. Estimation results based on households' inflation expectations from the Michigan Survey of Consumers support this hypothesis for US inflation and represent an alternative to professional forecasts.

Note 3: While Figure 1 is limited to the EA aggregate, the observation of uniform under- and subsequent overestimation is true for all individual EA11 countries alike.

Note 4: To account for HP filters' sensitivity to start and end points, trend GDP is derived from a longer time series of Q1 1980-Q4 2015. While sensitivity to the start point is thereby reduced, sensitivity to the end point potentially remains.

Note 5: Detailed variable descriptions and data sources are listed in the appendix.

Note 6: Error terms $\varepsilon_{t}$ and $\eta_{i t}$ with $i=1,2$ are constrained to allow convergence. Variations of these constraints are performed to avoid dependence on particular specifications. No dependence is observed, as variations do not change results in a noteworthy manner.

Note 7: Detailed estimation results of OLS as well as unrestricted hybrid NKPC estimations for the EA and EA11 are available upon request.

Note 8: Constraints of error terms described in Section 4 remain unchanged.

Note 9: On a minor note, coefficients $\gamma$ and $\lambda$ of EA and EA11 estimates are slightly smaller than median coefficients reported in listed related studies.

\section{Appendix: Variables and data sources}

\begin{tabular}{ll}
\hline Variable description & Sources \& comments \\
\hline HICP: Year-over-year change in HICP in \% & Eurostat \\
Q1 1990 - Q4 2015 & $\begin{array}{l}\text { OECD } \\
\text { HICP data complemented with CPI inflation from OECD in early } \\
\text { 1990s }\end{array}$ \\
\hline IFC: Survey measure of expected inflation for the & $\begin{array}{l}\text { Consensus Economics } \\
\text { coming four quarters ahead in \% }\end{array}$ \\
$\begin{array}{l}\text { Weighted average of current and coming year's expected } \\
\text { inflation in the first month of the respective quarter }\end{array}$ \\
\hline GAP: Output gap, deviation of GDP from HP-filtered & OECD \\
GDP in \% of HP-filtered GDP & $\begin{array}{l}\text { AMECO } \\
\text { Real GDP in €m, expenditure approach, seasonally and calendar } \\
\text { date adjusted } \\
\text { Qx1 1980 - Q4 2015 }\end{array}$ \\
& $\begin{array}{l}\text { depended to cover Q1 1980 - Q4 2015 to alleviate starting point } \\
\text { OECD data complemented with AMECO data }\end{array}$ \\
& $\begin{array}{l}\text { Annual NAIRU estimates are applied for the four quarters of the } \\
\text { respective year }\end{array}$ \\
\hline UGAP: Unemployment gap, deviation of harmonized \\
unemployment rate from NAIRU estimates
\end{tabular}

\section{Copyrights}

Copyright for this article is retained by the author(s), with first publication rights granted to the journal.

This is an open-access article distributed under the terms and conditions of the Creative Commons Attribution license which permits unrestricted use, distribution, and reproduction in any medium, provided the original work is properly cited. 